\begin{tabular}{|c|c|c|c|}
\hline & $\begin{array}{l}\text { Escola Superior } \\
\text { de Cestsooe } \\
\text { Techologia } \\
\text { [iPSantarém] }\end{array}$ & KL & $\begin{array}{l}\text { ISSN 2029-7564 (online) } \\
\text { SOCIALINĖS TECHNOLOGIJOS } \\
\text { SOCIAL TECHNOLOGIES } \\
2014,4(2) \text {, p. 292-305 }\end{array}$ \\
\hline
\end{tabular}

\title{
SMARTER GRID THROUGH COLLECTIVE INTELLIGENCE: USER AWARENESS FOR ENHANCED PERFORMANCE
}

\author{
Marcel Macarulla \\ GRIC, Department of Construction Engineering, Technical University of Catalonia, Spain, \\ marcel.macarulla@upc.edu \\ Michele Albano \\ CISTER/INESC-TEC, Polytechnic Institute of Porto, Portugal, mialb@isep.ipp.pt
} doi:10.13165/ST-14-4-2-04

\section{Abstract}

Purpose - This paper examines the scenario of a university campus, and the impact on energy consumption of the awareness of building managers and users (lecturers, students and administrative staff).

Design/methodology/approach - This study draws a comparison between direct fruition of the information by both skilled (building managers) and unskilled (users) recipients, and the effect of peer pressure and beneficial competition between users in applying the good practices. In fact, the usage of edutainment, implemented by the automatic publication on the Twitter platform of energy consumption data from different users, can promote general users' awareness on best practices and their effect on energy consumption. In addition, the use of a social network platform allows the interaction between users, sharing experiences and increasing the collective intelligence in the energy efficiency field.

Findings - Tests revealed that enhanced awareness helped managers to identify strategies that, if implemented in the whole building, could reduce energy consumption by about $6 \%$. The tests on university users' awareness hint that the expected energy savings can reach $9 \%$, in addition to the previous $6 \%$. In fact, the measures were implemented 
in one of the three common rooms, and at building level the total energy consumption decreased by 3.42\%, proving that a large deal of energy can be saved by capillary actions targeting society at large. The emerging collective intelligence of the final users ends up having a stronger effect on energy saving than the actions of more educated professionals.

Practical implications - The approach used in this paper moved the burden of evolving the energy saving strategies to new scenarios onto the collective intelligence of the users, by connecting the users - and their experiences in new scenarios - using a social network to provide guidelines to other users involved in the same decision processes.

Originality/Value - The authors of the paper use social technologies (Twitter, graphical interfaces) for a social goal (promote user awareness on energy usage) for the benefit of the society (energy savings).

Keywords - EMS, Key Performance Indicators, Energy efficiency.

Research type - research paper.

\section{Introduction}

Buildings represent a major link between society and the environment and are an essential element in any strategy designed to promote environmental sustainability (Gulbinas, 2014). In Europe, nearly $40 \%$ of final energy consumption and 36\% of the green house emissions are from buildings (EC, 2013), and it is expected that this percentage is bound to increase (Gangolells, et al., 2012). In this context, the EU is aiming for a 20\% cut in Europe's annual primary energy consumption by 2020 (Energy Efficiency Directive 2012/27/EU). According to IPCC (2007), buildings offer the largest share of cost-effective opportunities for greenhouse gas emissions mitigation among all the sectors.

Different strategies described in the literature can concur to reduce the buildings energy consumption. An example is the introduction of Energy Management Systems (EMS), which contributed to reduce buildings energy consumption with different degrees of success. However, the information tracked and stored by the EMS is rarely fully interpreted and used (Xiao and Fan, 2014). Another possible strategy is to carry out the energy user awareness. The occupants' behaviour has a great influence on the energy demand, management and consumption of a building (Meester, et al., 2013). Users' decisions and actions have a strong impact on the energy consumption and are an important factor in reducing energy consumption (Kashif, et al., 2013). In this context, the ENCOURAGE project explores the possibility to use the information from EMS to enhance user awareness (Albano, et al., 2013).

The increase of user awareness has been proved to have beneficial effects on energy usage (Coleman, et al., 2012). In the literature, different strategies to increase user awareness have been described, e.g., in Chena et al. (2014), where it is presented a visualization tool to determine user engagement with real-time and easily accessible information. Work of other authors, e.g., Wang and Taylor (2014), has presented how to use online social networking platforms to promote energy savings. 
This work considers using the smart grid platform developed in the context of the ENCOURAGE project (Albano, et al., 2013) to promote user awareness on energy consumption. User awareness is enhanced at two different levels: directly informing energy managers by using a visualization platform, and using social networks for both displaying energy consumption and recommending best practices for university campus users. For this purpose, a set of Key Performance Indicators (KPIs) was developed and used in a manner depending on the type of user. In the energy manager's case, which is considered to be well-educated in matters related to energy consumption and saving, the KPIs are displayed assuming that the user has enough skills to understand the meaning of the KPIs. In the university campus user's case, which is considered to be the general user what does not possess specialized knowledge on energy saving practices, messages concerning energy consumption are published automatically through the Twitter platform, to inform both the user and other campus inhabitants, regarding the good or bad practices in the building energy usage, ending up creating peer pressure and beneficial competition among users in applying the good practices.

The diffusion of energy saving practices using online social networking platforms can contribute to a substantial reduction in energy consumption (Wang and Taylor, 2014). The selected social network platform is Twitter. This platform allows users to follow other users (subscribe to other users' messages), have followers (allowing other users to subscribe to their messages) and write instant messages, to share experiences and discuss energy saving practices. The goal of enhancing users' awareness is to orchestrate implicitly their behaviors and distilling their (limited) understanding of the KPIs into the collective intelligence of the user group.

The rest of the paper is organized as follows. Sections 2 and 3 introduce the architecture of the ENCOURAGE platform and the Terrassa testbed, respectively. Later on, section 4 provides insights on how the research work was executed, in terms of Key Performance Indicators (KPIs) and algorithms. The KPIs were used to synthesize a view of how much energy was being wasted/saved and how well the testbed was performing and being used in general. The algorithms were used to decide what to inform the users about, with the goal of driving them into applying energy saving practices. Section 5 summarizes the results of the experimentation and their limits. Finally, section 6 draws conclusions on the results of the study and proposes future work.

\section{Encourage project architecture}

The ENCOURAGE project developed a user-side smart grid for the interaction of existing devices by different vendors, moving the most computationally expensive operations to the cloud. The ENCOURAGE platform considers the world divided into macro-cells, which are sets of buildings which are co-located in the same area, share the same environmental condition (weather), and can potentially exchange energy between themselves without recurring to an energy utility. The macro-cell is further divided into cells, which are residential/commercial space that pertains to the same user from the economical point of view. In a cell, a number of Home Area Networks (HANs) are 
deployed. Each HAN is composed of a number of embedded devices (sensors, actuators, etc.) and a Gateway. The latter is a device that is connected to the internet and is connected to the other embedded systems of the HAN via technologies that can span from Power Line Communication to Bluetooth, to $\mathrm{WiFi}$, to ZigBee, to other wireless and wired communication technologies. In general, the HAN functioning is defined by the vendor of the Gateway, and a cell can contain different HANs, e.g., one collecting data on the environment (temperature, humidity, user presence, lighting, etc.), one can monitor and control appliances (washing machine, lighting systems, etc.) and one can be entrusted with managing the renewable energy sources (rooftop photovoltaic systems, etc.).

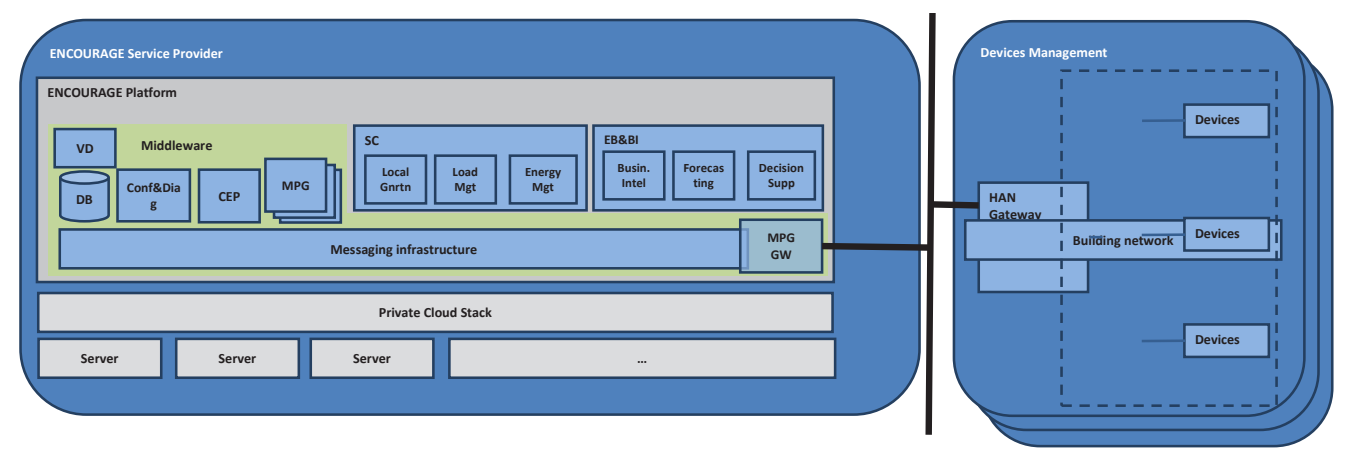

The ENCOURAGE smart grid platform is articulated into a set of components, and its structure is reported in Figure 1. ENCOURAGE is organized in a hierarchical manner, and its first level of decomposition is articulated into four logical blocks, which are "Devices Management", "Middleware", "Supervisory Control" (SC), and "Energy Brokerage and Business Intelligence" (EBBI). The underlying enabler is a Private Cloud Stack, which allows the ENCOURAGE platform to enjoy the elasticity of the grid in terms of computational power.

The Middleware logical block binds together the other components. Each logical block is composed of modules, which in some cases are divided into submodules. The decomposition of the architecture will be further developed in the next section.

The Device Management logical block manages all the interaction of ENCOURAGE platform with external entities. The internal protocol of ENCOURAGE is based on an international standard (IEC 61968 - Common Information Model, or CIM (IEC, 2013)), which semantic subsumes the semantics of most of other smart grid protocols, and thus represents the common language of the smart grid. Thus, the Device Management logical block connects to a number of Middleware Plug-ins (MPGs) that translate custom protocols into the CIM. In particular, the figure reports the MPG GW, which is any plugin for the HAN Gateways and translates the custom protocol used by a particular Gateway into the CIM. Still, a number of other MPGs provide added value to ENCOURAGE, e.g., the MPG that imports energy prices from energy markets, and is used to optimize energy acquisition. Other two MPGs that are particularly critical for the application described in this paper are the webservice MPG, which lets dashboards receive data to be displayed to 
energy managers, and the Twitter MPG, which exports messages related to energy usage to the Twitter platform.

The Middleware logical block comprises "Messaging Infrastructure", "Database”, "Complex Event Processor", "Configuration and Diagnostics" and "Virtual Devices" modules. The Messaging Infrastructure is a high performance event-based messaging system based on the AMQP protocol (Videla, 2011), which links the different ENCOURAGE components together. A database keeps historical data on everything happening in the grid. The Complex Event Processor (CEP) aggregates sensor reading into high-level complex event, to allow business logic to use complex events. The Configuration and Diagnostics module is responsible for the interaction with the configuration system used inside ENCOURAGE Cells. The Virtual Device (VD) module takes the roles of:

- cache, by keeping the current status of each sensor and actuator in the system, to provide the datum for querying components without contacting devices in user homes;

- database handler, by interacting with a database to keep a historical entry for each message that passes through the middleware;

- router, by relating the unique ID of a device to the gateway that must be reached to contact the device.

The EBBI logical block contains the Business Intelligence module, which performs reporting functions, to distill the data collected from the sensors in the HANs into reports regarding energy usage and efficiency of energy-saving measures. The information created by this module is later on provided to the users, by exporting them to the dashboards and to the Twitter platform by means of a specialized MPG.

The rest of the logical blocks of ENCOURAGE are less critical for the matter at hand, since they mainly provide the high performance needed for real-time functioning, while satisfying the functional requirements for a general purpose smart grid. The SC and the EBBI logical blocks provide intelligence to the smart grid, by computing the politics that improve the performance of the electrical grid.

For the application at hand, the most important data flows start in the sensor data are collected at HAN level by the Gateway, then they get into the ENCOURAGE Middleware through the MPG GW, are recorded/routed by the VD module, processed by the Business Intelligence module of the EBBI, and finally exported towards the dashboards and the Twitter social network by specialized MPGs.

\section{ENCOURAGE campus scenario description}

The scenario considered in the experimentation is the urban campus of the Polytechnic University of Catalonia (UPC) located in a small urban area (less than $0.15 \mathrm{~km}^{2}$ ) in the city of Terrassa (Barcelona), involving relatively high population and employment densities. Several activities take place close together in the facilities, blending educational, residential, commercial, industrial and other public building uses. 


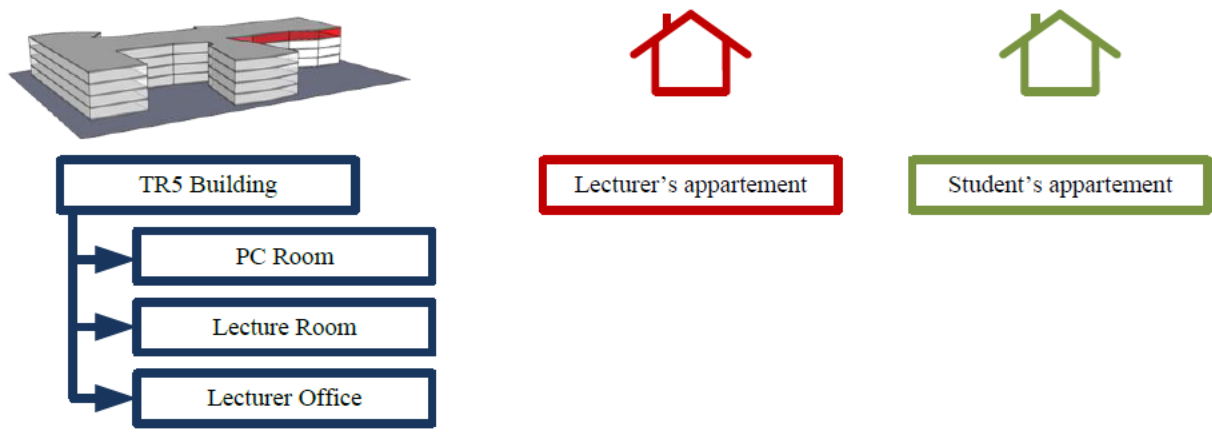

Figure 2. Testbed structure: Cells and rooms

The whole campus is considered a macro-cell, which comprises 3 cells: a building mainly devoted to academic usage with 2600 students, 240 lectures and administrative staff called TR5 building, a Student's apartment and a Lecturer's apartment. The building TR5 has 3 rooms: computer room, lecture room and lecturer office. The other two cells are not divided into rooms. The devices installed in the different cells and rooms send data to the ENCOURAGE platform, which processes the monitoring information, generates the dashboards and sends messages to the Twitter platform to report the energy consumption and to suggest best practices to reduce the energy consumption.

Four types of users can be identified in the campus scenario: lecturers, administrative staff, students and campus building managers. To understand the operation of the proposed system, some characters, subjects to actions taken by the system, are introduced:

Marc, a second year student in Terrassa School of Industrial and Aeronautical Engineering (Building TR5). He is currently pursuing a Bachelor's degree in Industrial Technology. Marc is 19 years old, and although he comes from Lleida, which is a town located quite close to Terrassa, he is currently living in the Students' Hall of Residence in Terrassa.

Sara, a PhD lecturer working in the Department of Construction Engineering in Terrassa School of Industrial and Aeronautical Engineering (Building TR5). She is 27 years old and comes from Tarragona, although during weekdays she lives in an apartment in the campus area.

Joseph, the energy manager of the campus buildings. He is responsible to reduce the energy consumption of the different buildings in the campus.

Student, which represents a generic character of a student of the Terrassa School of Industrial and Aeronautical Engineering in Terrassa.

\section{Research methodology}

In the previous work (Macarulla, 2014), the authors defined a technique to carry out the user awareness by means of a set of Key Performance Indicators (KPIs). The KPIs were developed following 3 steps in a top-down manner: i) define the main strategic objectives 
and scenario requirements, ii) identify the questions to answer, iii) design KPIs that will answer the former questions. The challenge was to create a set of KPIs to characterize and diagnose the buildings and detect bad and good practices in the building usage. The KPIs were meant to contribute to identifying the excessive energy consumption due to the inadequate usage of facilities or premises that have a higher consumption in comparison with similar ones. In addition, the KPIs allowed the comparison between different sized buildings or premises, different amount of users per building or premise, and the hours of usage of the buildings or premises. The main strategic objectives defined, the Key Performance Questions (KPQ) identified and the KPIs as revised in this novel work are presented in Table 1.

Table 1. Strategic objectives, KPQs and KPIs for the ENCOURAGE campus testbed

\begin{tabular}{|c|c|c|}
\hline Strategic objective & KPQ & KPI \\
\hline \multirow{15}{*}{$\begin{array}{l}\text { Increase energy } \\
\text { efficiency at device- } \\
\text { level, building-level, } \\
\text { district level }\end{array}$} & \multirow{2}{*}{$\begin{array}{l}\text { Are we increasing energy efficien- } \\
\text { cy of the building/macro-cell? }\end{array}$} & Energy savings \\
\hline & & Energy savings rate \\
\hline & \multirow{3}{*}{$\begin{array}{l}\text { Are we increasing energy } \\
\text { efficiency of the appliances? }\end{array}$} & Stand-by power \\
\hline & & Hours of stand-by \\
\hline & & Appliances consumption per category \\
\hline & \multirow{7}{*}{$\begin{array}{l}\text { Where can we improve energy } \\
\text { optimization? }\end{array}$} & Consumption $/ \mathrm{m}^{2}$ \\
\hline & & Consumption/occupant \\
\hline & & Consumption/DD \\
\hline & & Consumption/(occupant.m².DD) \\
\hline & & Optimizable part of consumption \\
\hline & & Appliances time of use \\
\hline & & Consumption $/ \mathrm{m}^{2}$ \\
\hline & \multirow{2}{*}{$\begin{array}{l}\text { Are the consumption patterns } \\
\text { consistent? }\end{array}$} & Consumption per hour type \\
\hline & & Consumption per day type \\
\hline & $\begin{array}{l}\text { Are we increasing overall } \\
\text { sustainability? }\end{array}$ & CO2 savings \\
\hline \multirow{2}{*}{$\begin{array}{l}\text { Good user comfort } \\
\text { levels }\end{array}$} & \multirow{2}{*}{$\begin{array}{l}\text { Is the user comfort being } \\
\text { compromised? }\end{array}$} & Internal temperature variability \\
\hline & & Internal humidity variability \\
\hline \multirow{2}{*}{$\begin{array}{l}\text { Economic } \\
\text { optimization }\end{array}$} & \multirow{2}{*}{ Are we decreasing the total costs? } & Costs savings \\
\hline & & Costs per kWh consumed \\
\hline
\end{tabular}

The proposed user awareness methodology is developed at two levels: energy managers and university campus users (See Figure 3). The energy consumption awareness of campus building managers is addressed by taking into consideration the estimation done by the Business Intelligence module (described in Section 2) and the associated dashboards. With the aim to display the KPIs to the energy manager, different visualization techniques were studied and tested. This paper focuses on the experience of a group of energy managers using the developed set of KPIs, visualized in a web-platform, to characterise, diagnose and identify potential improvements in how energy is used in the 
buildings under consideration. In addition to the automatic visualization of the results of the Business Intelligence analysis, the experiments described in this paper involve that the campus building managers use an account on the Twitter platform and post best practices to reduce the energy consumption. The promotion of the interaction between the building managers' and building users can cause the emergence of more communication between users, who discuss the results of their actions on energy saving and best practices, leading to the emergence of collective intelligence of the users set intended as a community, which will be referred in the following as the ENCOURAGE community.

The energy consumption awareness of ENCOURAGE community (university campus users) is carried out using social media technologies to provide information on the actual energy consumption to ENCOURAGE community itself. In addition, the energy consumption provided to the building users is complemented with information on best practices to reduce energy consumption. Energy consumption in the different campus cells and rooms is reported, and best practices in the sustainable use of public buildings are promoted by the system. Providing this, information to the building users was expected to lead to a reduction in energy consumption.

With the aim to respect the privacy of the different users, by default the information related to cells or rooms belonging to only one responsible user was private, in the sense that the ENCOURAGE platform sent direct messages to the Twitter account of the responsible user only. The user could then decide to allow the ENCOURAGE platform to post the messages directly to the public feed, post the message manually, or do nothing to safeguard privacy.

An algorithm was developed to decide which messages have to be published in each moment, depending on the calculated KPIs and the rules that evaluate them. As reported in Table 2, two types of messages were defined: messages reporting historical events and messages reporting real time events.

Table 2. Examples of messages send by the ENCOURAGE system to the Twitter platform (translation from the Catalan language)

\begin{tabular}{|l|l|l|}
\hline \multicolumn{1}{|c|}{ Rule } & \multicolumn{1}{|c|}{ Message } & Periodicity \\
\hline $\begin{array}{l}\text { If PC room energy consumption from } \\
\text { this week is higher than } 1,05^{\star} \text { PC room } \\
\text { energy consumption from last week, } \\
\text { then send one of these messages }\end{array}$ & $\begin{array}{l}\text { Dear PC room users, the energy } \\
\text { consumption has increased by } \\
\text { [value] \% this week. Remember } \\
\text { to make the most of solar light } \\
\text { whenever possible. }\end{array}$ & Weekly \\
\cline { 2 - 3 } & $\begin{array}{l}\text { Dear PC room users, the energy } \\
\text { consumption has increased by } \\
\text { [value] \% this week. If you see any } \\
\text { unnecessary light turned on, please } \\
\text { turn it off. }\end{array}$ & \\
\hline $\begin{array}{l}\text { If not scheduled lecture and current } \\
\text { lectures room energy consumption is } \\
\text { higher than } 1,05^{\star} \text { lecture room energy } \\
\text { consumption per type of hour and no } \\
\text { movement has been detected during the } \\
\text { last half an hour, then send this message }\end{array}$ & $\begin{array}{l}\text { It seems that lights in the lecture } \\
\text { room [name of the room] are } \\
\text { turned on, and nobody is inside. If } \\
\text { anyone is nearby, please turn off the } \\
\text { lights. }\end{array}$ & $\begin{array}{l}\text { Event-based } \\
\text { (any time that } \\
\text { users action } \\
\text { match the } \\
\text { rule) }\end{array}$ \\
\hline
\end{tabular}


The social media technology selected to carry out the experiments was Twitter. Twitter allows posting messages either privately or publicly, with a maximum length of 140 characters. Since the test case was performed in Terrassa (Barcelona), the language used for publishing messages was Catalan.

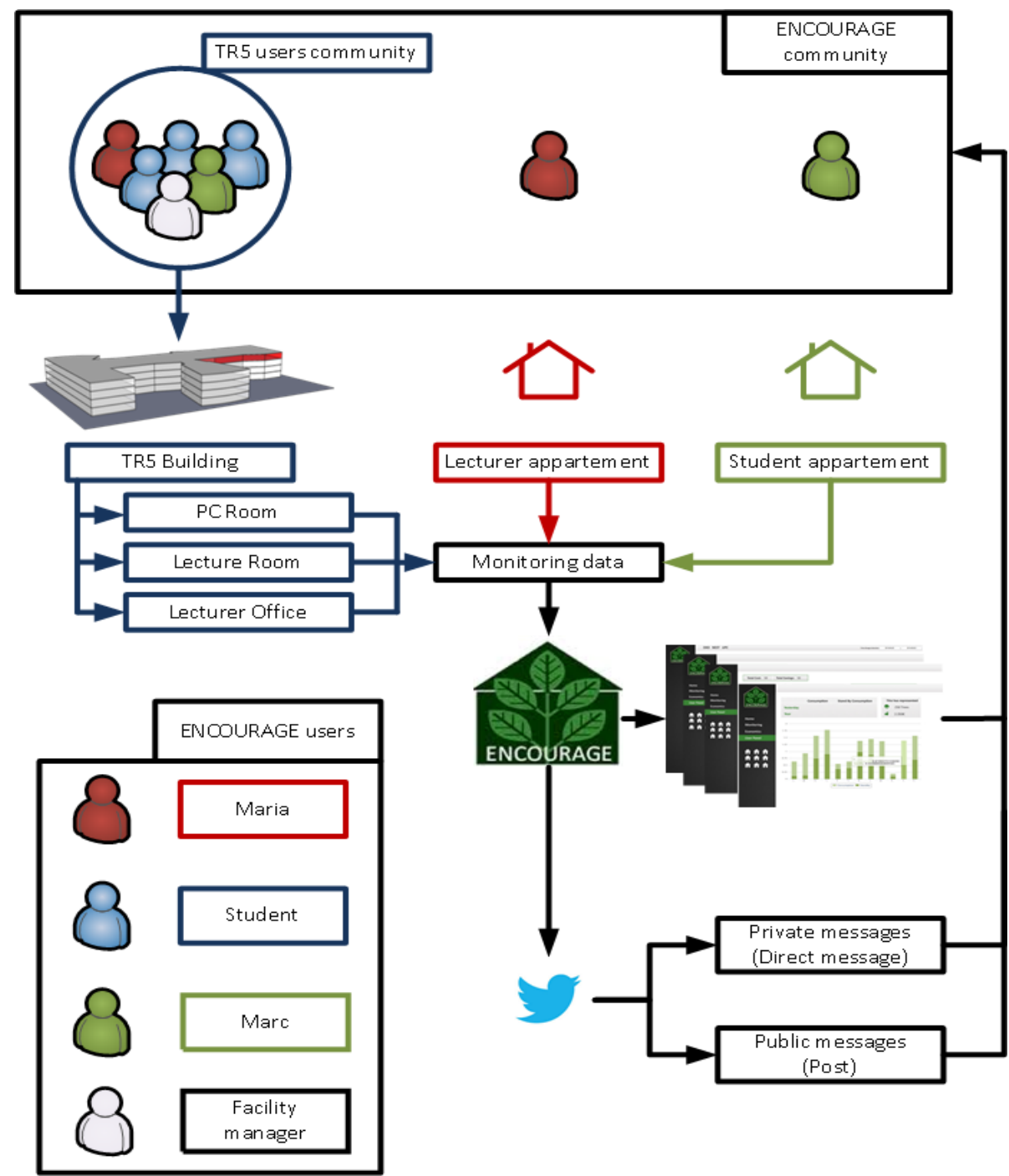

Figure 3. Energy awareness approach

The strategy involved that campus users followed the ENCOURAGE Twitter account to receive messages related to the energy consumption and best practices. In addition, the users were able to share experiences and discuss energy saving practices. The goal of this process is to convert the KPIs into understandable collective information related to the energy efficiency, to lower the minimal level of knowledge of energy efficiency that was needed for a user to contribute to the functioning of the group. The intended result 
was that more users were going to add their efforts to understanding how to optimize energy usage, causing the collective intelligence of the user group to grow. The results, which will be presented in the next section, are expected to show that this process aided building energy consumption to decrease without compromising users' comfort.

\section{Results and findings}

By applying the methodology described in this paper, the energy managers of the testbed identified different energy efficiency improvements to update the configuration of the building. The KPI "stand-by power" allowed energy managers to identify malfunction of connected loads in the computer room. The stand-by power KPI was near $0,5 \mathrm{~kW}$, due to the computers connected to the electrical grid in the room. Since the computer room contains 30 computers, the average stand-by power for each computer is $16,67 \mathrm{~W}$. This value is very high compared with the normal stand-by power for a computer, which should be between 3 to $15 \mathrm{~W}$ (Sahin and Koksal, 2014). The managers visited the room and detected that the computer screens were obsolete CRT screens, which have high stand-by power consumption. These computers are planned to be changed into a new configuration during the next year, also as a result of the analysis described in this paper.

The "stand-by power" KPI and the "hours of stand-by" also allowed managers to identify that the computer rooms were consuming energy that could be saved by cutting the electricity off during nights, weekends and holidays. The "hours of stand-by" of the computer rooms amounted to 15 hours per day (from $10 \mathrm{pm}$ to 8 am on working day, plus weekends and holidays), suggesting that cutting electricity off in the rooms could have a stronger effect than relying on the stand-by power of modern computers. During a 9-days period, the computer room's energy consumption was $3420,91 \mathrm{kWh}$. Cutting the electricity during closing periods, the estimated energy savings were more than $916 \mathrm{kWh}$, meaning a $26 \%$ of reduction with no burden on the users. Estimating the savings for the whole year, the potential reduction in one computer room is about $35 \%$. The impact on the whole building is a reduction of $1,02 \%$ of the total building energy consumption. If this strategy is applied in all computer rooms in the building, the potential energy consumption savings for the whole building is about 6\%. As experimentation, this strategy was implemented in one PC room during 2 months, achieving the expected savings.

The indicator "stand-by power" for the lecturer office averaged to $100 \mathrm{~W}$. The energy managers asked the lecturers to use information on the dashboard and decide if they can disconnect appliances. The lecturers unplugged 5 appliances that they do not use usually (one printer, one paper shredder, one wireless telephone, one computer and one screen). In addition, they took care to unplug the mobile phone charger when it was not used. This measure reduced the average stand-by power from $100 \mathrm{~W}$ to $46,67 \mathrm{~W}$. Taking into account that on average the lecturer office was spending 38,57 kWh in one week, the savings due to this measure are around $23,96 \%$ of the lecturer office energy consumption. The ENCOURAGE platform is currently sending private messages to report energy saving achievements to the lecturer office users. The building managers estimate that 
if this measure is applied in the whole building, the building energy consumption can decrease by around $2,31 \%$. The energy managers asked the lecturers to post this message on Twitter to share this experience, but until this moment the lecturers have not accepted to do so.

The indicator "stand-by power" is close to 0 in the lecture room. This is an expected result since in this room no devices are usually plugged-in. The whole energy consumption of this room is due to lighting, and energy managers detected that the energy consumed during non-lecture hours is very close to the energy consumption during the lecture hours. Managers monitored the usage of this room for one week and they detected that the last student or lecturer to leave the room did not usually turn off the lights. It is difficult to calculate the exact quantity of wasted energy because sometimes the students use the room to carry out meetings or to do group work. For this reason, managers saw energy saving potential and tried to exploit user awareness as proposed in this work. However, after one month of experimentation, the energy consumption in the room was not reduced, meaning that the informative messages were ignored by the room's users.

It was not possible to compute the "energy consumption per user" KPI because it was impossible to implement a large scale monitoring of the number of persons of the scenario, with the limited budget at the disposal of the energy managers. The calculation of the KPI "energy consumption per degree day" was irrelevant because the HVAC system is controlled by the central campus services, and thus, it was not possible to experiment with it.

The impact of the Twitter usage to carry out the energy user awareness in the computer rooms and the lecturer rooms was very limited. The energy savings are not appreciable right now. The students are not following the Twitter profile and they are not watching the dashboards. The managers agreed to study, in a future work, how they can involve the students and promote the usage of the information provided by the ENCOURAGE platform. On the other hand, in the lecturer office it was possible to appreciate changes in the users' behavior. For example, the energy load curve showed that the room users are now turning off the lights when they leave the rooms to have lunch, and the hours of usage of the lighting system got slightly lower. On average, the energy saving was around 3,30 kWh per week, meaning an energy reduction of around $8,56 \%$ in the lecturers' office. The managers estimated that if all users changed their behavior in the same way as the lecturer office users, the building energy consumption could be reduced by around $1,11 \%$.

The data presented above were preliminary in the sense that the actors were currently working actively to lower their energy consumption. More work is needed to assess the long-term effect of ENCOURAGE, and whether and how much the best practices can become part of the business-as-usual life of the campus. The first result obtained on the long term effects regards the changes in the users' behavior of the lecturer office. After an evaluation period of eleven weeks, the lighting energy load curve showed that the energy savings in the lighting system were persistent. During the baseline period, the lighting energy load curve was constant during the whole day at $0,44 \mathrm{kWh}$, the lights were turned on at the beginning of the day and were turned off at the end of the day. During eleven weeks, after the implementation of the system, the lighting energy load curve presented 
different values $(0,120 \mathrm{kWh}, 0,31 \mathrm{kWh}$ and $0,44 \mathrm{kWh})$ at different times of the day. These results revealed that the users were turning on and off the lights depending on their needs, even after the users got accustomed to the ENCOURAGE system. The total energy consumption in eleven weeks due to the lighting system was $178,63 \mathrm{kWh}$. To estimate the energy savings during these eleven weeks and to avoid the occupancy corrections, savings were calculated as a difference from a constant consumption value of $0,44 \mathrm{kWh}$ (the baseline before implementation of ENCOURAGE). During these eleven weeks, if the users did not manage the lighting system, the energy consumption should have been $212,59 \mathrm{kWh}$. The system allowed a reduction of $15,97 \%$ in the lighting system energy consumption.

Table 3. Energy consumption data regarding the considered scenario

\begin{tabular}{|l|c|c|c|c|c|}
\hline & $\begin{array}{c}\text { Building } \\
\text { (estima- } \\
\text { tion) }\end{array}$ & $\begin{array}{c}\text { Macro- } \\
\text { cell }\end{array}$ & $\begin{array}{c}\text { Lecturer } \\
\text { office }\end{array}$ & $\begin{array}{c}\text { PC } \\
\text { room }\end{array}$ & $\begin{array}{c}\text { Lecture } \\
\text { room }\end{array}$ \\
\hline $\begin{array}{l}\text { Average consumption during the testing } \\
\text { period (kwh) }\end{array}$ & 6000,00 & 222,28 & 38,57 & 152,01 & 31,70 \\
\hline $\begin{array}{l}\text { Savings due to the changes of behavior } \\
\text { (kWh) }\end{array}$ & 204,40 & 12,54 & 12,54 & 0,00 & 0,00 \\
\hline Improvements (kWh) & 360,07 & 75,25 & 0,00 & 75,25 & 0,00 \\
\hline Total (kWh) & 564,47 & 87,79 & 12,54 & 75,25 & 0,00 \\
\hline Savings due to the changes of behavior (\%) & 3,41 & 0,0564 & 32,51 & 0,00 & 0,00 \\
\hline Improvements (\%) & 6,00 & 33,85 & 0,00 & 49,50 & 0,00 \\
\hline Total (\%) & 9,41 & 39,50 & 32,51 & 49,50 & 0,00 \\
\hline
\end{tabular}

\section{Conclusions}

This paper presents a novel approach to distill KPIs from data tracked by EMS, and proposes ways to take profit from this information. The approach adapted delivery of KPIs data to their intended recipient. The authors of this paper move the burden of evolving the energy saving strategies to new scenarios onto the collective intelligence of the users as a community, by connecting the users - and their experiences in new scenarios - using a social network to provide guidelines to other users involved in the same decision processes. Bottom line, the authors use social technologies (Twitter, graphical interfaces) for a social goal (to promote user awareness on energy usage) for the benefit of the society (energy saving).

The KPIs developed can be used to improve the energy user awareness in practical scenarios, and lead to (measurable) energy saving in a building. On the long run, the developed KPIs can help identifying and prioritizing which building areas are suitable to improvement in terms of energy efficiency. The usage of edutainment to target the final users can enhance the effect of data by promoting general users' awareness on 
best practices and their effect on energy consumption. In addition, the usage of a social network platform allows the interaction between users, sharing of experiences, and increase of the collective intelligence in the energy efficiency field.

The first tests revealed that the enhanced awareness helped energy managers to identify strategies to reduce building energy consumption by about $6 \%$. The results on the lecturer offices hinted that the energy savings can be over 3\%. Currently, the research project is failing in the target to involve the students in the scenario. The managers identified that the main problem is that the ENCOURAGE project was not sufficiently advertised, and thus, the students either ignored the existence of the dashboards/ Twitter feed on energy usage, or regarded them as not important. One of the next steps that the research team will carry out will be to study how to involve the students in the campus scenario, with the aim to prove that more energy can be saved by capillary actions targeting society at large, instead of supporting just energy managers' decisions. A collateral effect of this future work is the proof that the emerging collective intelligence of the final users as a community ends up having a stronger effect on energy saving than the actions of a small number of more educated professionals.

\section{Acknowledgments}

This work was supported by EU Artemis JU funding, within the ENCOURAGE project, JU grant Nr. 269354, and by National Funds in Portugal (through the Portuguese Foundation for Science and Technology, Ref. ARTEMIS/0002/2010) and Spain in the Artemis program.

\section{Bibliography}

Albano, M.; Ferreira, L. L.; Le Guilly, T.; Ramiro, M.; Faria, J. E.; Dueñas, L. P.; Ferreira, R.; Gaylard, E.; Pelegrin, F.; Roarke, E.; Lux, D.; Scalari, S.; Sørensen, S. M.; Gangolells, M.; Pinho, L. M.; Skou, A. The ENCOURAGE ICT Architecture for Heterogeneous Smart Grids. IEEE EUROCON Conference, 2013, p. 13831390.

Chena, V.; Delmas, M., and Kaiser, W. Real-

Time, Appliance-Level Electricity Use Feedback System: How to Engage Users? Energy and Buildings. 2014, 70: 455-462.

Coleman, M.; Brown, N.; Wright, A.; Firth, S. K. Information, Communication and Entertainment Appliance Use - Insights from a UK Household Study. Energy and Buildings. 2012, 54: 61-72.
EC. Financial Support for Energy Efficiency in Buildings, Report from the Commission to the European Parliament and the Council. 2013 [interactive]. [accessed on 11-03-2014]. <http://ec.europa.eu/energy/efficiency/ buildings/doc/report_financing_ee_ buildings_com_2013_225_en.pdf >.

European Commission. Energy Efficiency Directive 2012/27/EU [interactive]. <http:// ec.europa.eu/energy/efficiency/eed/eed_ en.htm>.

Gangolells, M.; Casals, M.; Fuertes, A. Exploring the Possibility of Promoting Energy Conservation Behaviors in Public Buildings within the ENCOURAGE Project. ECCPM. Reykjavik, Island, 25-27 July 2012, p. 723-729. 
Gulbinas, R., and Taylor, J. E. Effects of RealTime Eco-Feedback and Organizational Network Dynamics on Energy Efficient Behavior in Commercial Buildings. Energy and Buildings. 2014, 84: 493-500.

International Electrotechnical Commission. IEC 61968-11 - Common Information Model (CIM) Extensions for Distribution, ed. 2.0. March 2013.

Kashif, A.; Ploix, S.; Dugdale, J., and Le, X. H. B. Simulating the Dynamics of Occupant Behaviour for Power Management in Residential Buildings. Energy and Buildings. 2013, 56: 85-93.

Meester, T.; Marique, A.; Herde, A. D., and Reiter, S. Impacts of Occupant Behaviours on Residential Heating Consumption for Detached Houses in a Temperate Climate in the Northern Part of Europe. Energy and Buildings. 2014, 57: 313-323.

Metz, B.; Davidson, O.R.; Bosch, P.R.; Dave, R., and Meyer, L.A. (eds.). IPCC. Climate Change
2007: Mitigation. Contribution of Working Group III to the Fourth Assessment Report of the Intergovernmental Panel on Climate Change. Cambridge: Cambridge University Press, 2007.

Sahin, M.C., and Koksal, M.A. Standby Electricity Consumption and Saving Potentials of Turkish Households. Applied Energy. 2014, 114: 531-538.

Videla A., and Williams J.W. RabbitMQ in Action: Distributed Messaging for Everyone. MEAP Edition, Manning Early Access Program, 2011.

Wang, Q., and Taylor, J. E. Energy Saving Practice Diffusion in Online Networks. Energy and Buildings. 2014, 76: 622-630.

Xiao, F., and Fan, C. Data Mining in Building Automation System for Improving Building Operational Performance. Energy and Buildings. 2014, 75: 109-118. 